\title{
A Brief Review on Covid-19 Effects in Children and Treatment Methods
}

\author{
Vaishnavi Tammishetty*1, Sravika Nagamalla², Pravalika Sakilam ${ }^{3}$, Hyma Ponnaganti ${ }^{4}$ \\ 1,2,3: Department of Pharmaceutics, Sarojini Naidu Vanita Pharmacy Maha Vidyalaya, Hyderabad, Telangana, India. \\ 4: Associate Professor, Department of Pharmaceutics, Sarojini Naidu Vanita Pharmacy Maha Vidyalaya, Hyderabad, Telangana, India. \\ *Corresponding author's E-mail: vaishnavivaishnavi694@gmail.com
}

Received: 05-07-2021; Revised: 18-08-2021; Accepted: 26-08-2021; Published on: 15-09-2021.

\section{ABSTRACT}

As there is an outbreak of novel corona virus in 2019 it has spread globally that resulted in severe acute respiratory syndrome coronavirus 2 (SARS-COV-2) pandemic and mostly there is limited data provided on children. The main aim of this review is to provide a knowledge on introduction, epidemiology, pathogenesis, transmission, clinical manifestations, laboratory findings, treatment of COVID-19 in children. And it also includes latest statistical data of children prone to COVID-19. Besides respiratory and GI symptoms atypical features such as chilblains and multi-inflammatory system are also reported. pathophysiology gives information regarding the life cycle of virus in hostcell and epidemiology explains the different types of viruses affecting the respiratory system. The clinical signs and symptoms are almost similar to the adults but they are in mild, and most of the children affected with Covid-19 are asymptomatic. This review study makes a medical practitioner to have a quick, practical approach to the disease to use in different scopes, especially in pediatric medicine.

Keywords: Covid-19, epidemiology, transmission, treatment methods.

QUICK RESPONSE CODE $\rightarrow$

DOI:

10.47583/ijpsrr.2021.v70i01.018

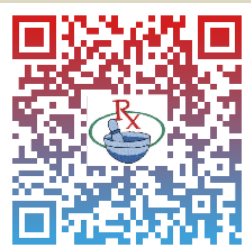

DOI link: http://dx.doi.org/10.47583/ijpsrr.2021.v70i01.018

\section{INTRODUCTION}

\section{Background:}

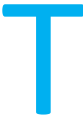

he first outbreak of corona virus has started in Wuhan, city of Hubei province in China 2019. Many cases have been reported for pneumonia, the reason for many cases is unknown initially later on the etiology of the causative organism is corona virus is known by the health commission of Hubei ${ }^{1,3}$. There are further studies had done and it's confirmed that main causative organism is novel corona virus with almost $85 \%$ of genomic identity of bat SARS like virus ${ }^{4,5}$. This coronavirus has spread worldwide and became a pandemic on march 112020 , it is officially declared as pandemic by World health organization $^{1,2}$.

SARS-cov2, mainly belongs to a Beta-coronaviruses and it belongs to family coronaviridae. There are few viruses like Hcov -229E, -HLCU1, -NL63, -OC43these virus has ability to circulate in body and it causes mild respiratory infections whereas the SARS cov- 2 it undergoes few mutations, and change in its structure and undergoes recombination's all this had led to the development of novel corona virus it can easily transmitted from animals to humans that causes severe respiratory diseases. ${ }^{3}$
Most of the children's who are affected with covid have shown symptoms or asymptomatic and mild symptom like nearly, less than $10 \%$ to $20 \%$ have shown symptoms for corona virus and requirement of hospitalization. Whereas $1-3 \%$ of children are affected more and the requirement of intensive care to children. And few children have shown multi-inflammatory syndrome. ${ }^{6}$

\section{Structure of coronavirus:}

1. They are large, enveloped, RNA viruses. ${ }^{1}$

2. Coronavirus-Its structure is a member of coronaviridae, nidoviral.

3. Subfamily-Coronavirinae also called as corona viruses. $^{7}$

4. The virus is spherical elliptic consisting of $60-140 \mathrm{~nm}$ in diameter mainly it is pleomorphic. ${ }^{1}$

5. This type of viruses mainly consists of mRNA as genome with 26-32 kilobases. The mRNA has 5'cap and 3 'poly $(A)$ tails the main use of it is for translation of polyprotein replica. ${ }^{7}$

6. Virus genome is mRNA it consists of 6-11 open reading frames (ORF).

7. The genome or virus consists of ORF $1 a / b$ it nearly codes for 16 non-structural proteins but mainly $\mathrm{S}, \mathrm{N}$, $\mathrm{M}, \mathrm{E}$ are considered as essential structural and they encode the remaining of genome.

8. In this protein the $S$ protein binds to the ACE2 receptors of the host cell and $\mathrm{N}, \mathrm{E}$ proteins mainly interfere with the immune response of the host. 
9. M protein it mainly helps in the transferring of the transmembrane nutrients. ${ }^{8}$

10. S proteins consists of subunits like S1 and S2. The main function of S1 is to interact with ethe ACE2 receptors for the entry in to the host cells and the function of the $S 2$ is to involve the fusion of the membrane through the HR1 and HR2 (heptad repeat). ${ }^{9,10}$

\section{Pathophysiology: ${ }^{6,11}$}

Mainly the pathogenesis of covid-19involves 4 stages like entry of virus and attachment, expression of the protein replicase, replication of the virus and transcription, and assembly of the virus and release. For the attachment of the virus to the receptors mainly there is an involvement of the S-protein to the receptor site it causes the first attachment of virus to the receptor site. After the attachment of protein, the protease in host cells gets cleaves that leads to the activation of protein attached to the receptor. This type of activation mainly depends on the availability of the protein. For the attachment there is a requirement of peptidase for binding to receptor for protein. once the virus enters in to the host cell the virus gets uncoated and the genome of virus enters in to the cytosol of the host cells. The virus genome is RNA it is 5'Methylated caps and 3'poly adenylated tail. These RNA's are translated by the ribosomes of the host cells. The genetic variability is the main part of the genetic recombination. The more no. of the proteins is released by the cells due to translation of mRNA of virus by the ribosome of the host cells. Usually, the viruses consist of the S, E, M proteins. The virus along with the proteins enters in to Golgi apparatus and the M protein involves in the initiation of the protein-protein interaction for the assemblage of the viruses. And its binding to the nucleocapsid then the viruses are released by exocytosis by the vesciles. Once the viruses are released and next, they infect other fresh host cells.

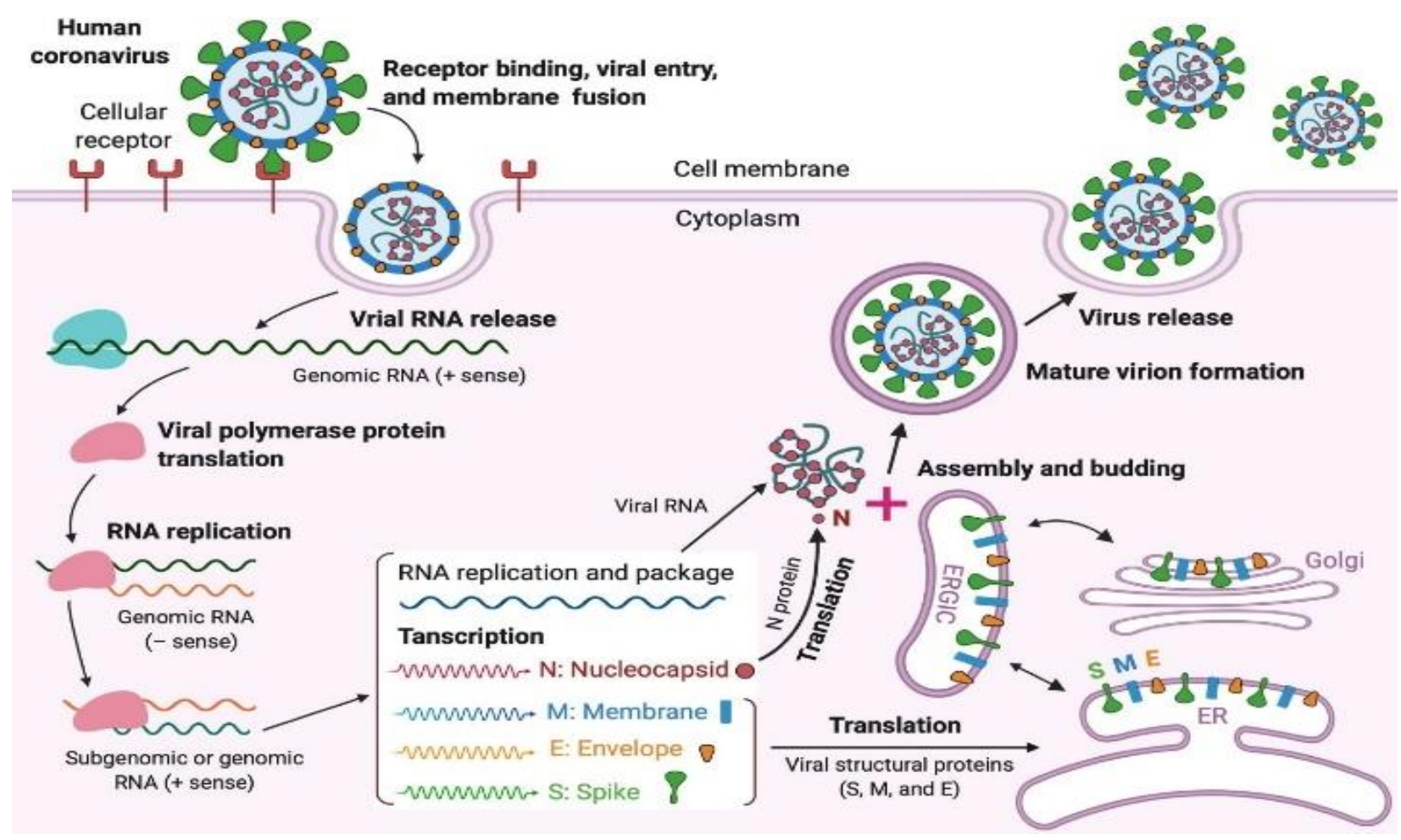

Figure 1: Pathogenesis of sarscov ${ }^{2}$

\section{Epidemiology: ${ }^{12}$}

\section{Common circulating HCOV:}

It occurs mainly in the children with 4 to $6 \%$ with acute respiratory syndrome. And, mostly children are hospitalized and $8 \%$ of children in outpatient's department. These types of viruses are seen in a child with the heart disease under the age of 3 . And even children with $11-46 \%$ are affected with the co-infections with the other virus which affect the respiratory system like adeno, Rhino, influenza, RSV. The infection in children with chronic conditions have shown more effect compared to the coinfection in children.

\section{SARS-COV-MERS-COV:}

i. SARS-COV: It belongs to the novel group of $2 b$ bacteriovirus it is firstly seen in the Guangdong province in south China in 2002, from their it eventually Spreaded to many countries.it mainly infects the lower respiratory tract mostly $50 \%$ of people above 60 years of age are infected. And it is easily transmitted from person to person. Nearly 29 countries had affected.

ii. MERS-COV: It belongs to the bacteriovirus occurred first in Saudi Arabia in 2012. It is easily transmitted from person to person. And mainly it affects the lower respiratory tract wit 20 to $20 \%$ of cases are reported it 
was an endemic in the middle east region. later years in 2014 it has seen in south Korea infected with 186 patients later it is infected to many people nearly 27 countries had affected.

iii. SARS-COV-2: Its outbreak has caused transmission of virus from person to person. And its incubation if for 5 6 days. When outbreak had occurred, there were numerous cases of pneumonia had been reported in China, Italy, Iran. By august, 2020 there were severe cases in southern states of India nearly millions of cases had been reported there was a high risk of transmission among children and young adults. The Ro indicates the number of people infected can infect other persons. The reproductive number of people who are affected with corona virus can infect approximately with 2.2. this number indicates the virus is transmitted from person to person. Recently it has shown there are increased cases due to increase in infectious nature of virus. And lack of testing kits and lack of awareness.

\section{Transmission in children:}

After the respiratory tract infection children are more prone to hospitalize mainly, they are affected due to influenza, syncytial virus. In children there is no proper development of the respiratory system and the immune system it is thought that there is a high risk of infections. ${ }^{13}$

In Wuhan there was their pediatric series are reported 171,20 and 10 children after the incubation period of 2-14 days the children had become symptomatic. In 171 children's series with RT-PCR they have confirmed to SAR COV-2 it has shown with signs and symptoms like cough, diarrhea, vomiting, fatigue etc. asymptomatic infection, pneumonia, upper tract infection has shown and one child had died.

There are $72 \%$ children with mild symptoms, and upper respiratory syndrome and positive PCR test. And $22 \%$ of children with moderate symptoms associated with fever, cough, fatigue, headache, myalgia. The persons with diabetes, hypertension, chronic respiratory disease, aplastic anemia they are more risk to infection. $73 \%$ of pediatric patients have shown fever, cough, dyspnea and $5.7 \%$ are hospitalized according to US CDC. ${ }^{1}$

\section{CLINICAL MANIFESTATIONS}

There is a systemic organ involvement in children with COVID-19. It includes the following:

\section{Signs and symptoms.}

1. In Case of Neurological Issues in Children:

Headache, altered mental status and weakness are the most common.

Demyelinating disease, stroke and encephalopathy.

Multi inflammatory syndrome (MIS), seizure, coma, aseptic meningitis. ${ }^{14}$

2. In Case of Cutaneous Manifestations in Children:
Macules and papules, vesicles/varicelliform like eruption.

Urticarial eruption, acral pseudo chilblain.

Erythema multiform, MIS in children.

3. In Case of Cardiac System:

Raised troponin / brain natriuretic peptide (BNP).

Myocarditis / pericarditis, valvulitis.

Pericardial effusion, coronary artery dilation / aneurysm.

Shock (requiring inotropic support).

4. In Case of Respiratory System:

Pneumonia, Acute respiratory distress syndrome (ARDS), pleural effusion.

5. In Case of Dermatologic manifestations:

Kawasaki like eruption.

6. In Case of Ophthalmics:

Conjunctivitis, non-suppurative / non purulent.

7. In Case of Renal System:

Acute kidney injury, proteinuria, hematuria.

8. In Case of Hematologic manifestations:

Coagulopathy (including thrombosis), leukocytosis, raised inflammatory markers (ferritin).

9. In Case of Gastrointestinal Tract:

Children with COVID-19 can be asymptomatic or present with fever, dry cough, fatigue and sometimes Gl symptoms such as Diarrhea, vomiting, nausea.

Abdominal pain / discomfort, transaminitis, ascites.

Hepatosplenomegaly, colitis / ileitis. ${ }^{15}$

\section{Laboratory Findings:}

- In case of cutaneous manifestations:

Histopathologic analysis of the erythema multi form like eruptions revealed a superficial and deep perivascular and peri eccrine inflammatory infiltrate with immune histo chemistry (IHC) demonstrating cytoplasmic granular positivity to the SARS-COV / SARS-COV 2 spike protein in endothelial epithelial eccrine glands.

Pediatric patients presenting with cutaneous manifestations of COVID-19 may also have a false negative PCR nasopharyngeal / oropharyngeal swab, yet are harboring COVID-19. ${ }^{15}$

- In case of hematological manifestations:

Laboratory findings from children are similar with infections caused by different novel COV's. The WBC count is typically normal or reduced with decreased neutrophil and lymphocyte count. Thrombocytopenia may occur. 
In severe cases, elevated liver enzymes, lactate dehydrogenase levels, as well as an abnormal coagulation and elevated D - dimers have been reported. ${ }^{16}$

\section{Radiological Findings:}

CT changes observed in children infected with SARS-COV 2 include bilateral multiple patchy, nodular ground glass opacities, speckled ground glass opacities and / infiltrating shadows in middle and outer zone of the lung or under the pleura. These findings are unspecific and milder compared with those in adults. ${ }^{17}$

\section{Statistical data of children prone to covid-19:}

Over 7,100 children and adolescents died from COVID-19, which is 0.3 percent of the 2.4 million COVID-19 deaths in 78 countries.

The 2.4 million COVID-19 deaths in 78 countries account for 68 percent of the total global deaths reported by Johns Hopkins University. COVID-19 data were collected from January 2020 to present and country data were updated on different dates.

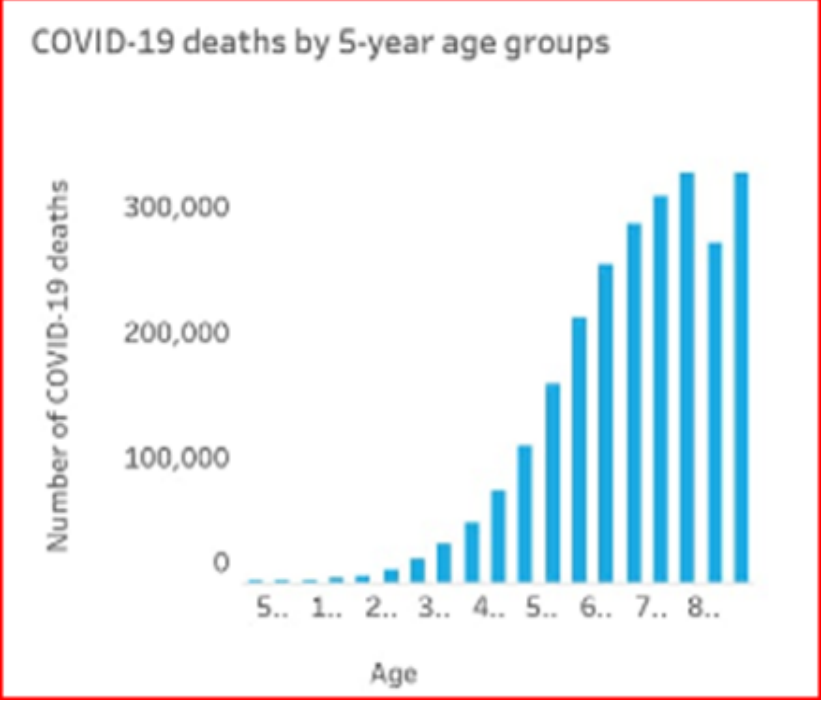

Figure 2: Covid-19 deaths by 5 year age groups

COVID-19 confirmed cases by 5 -year age groups

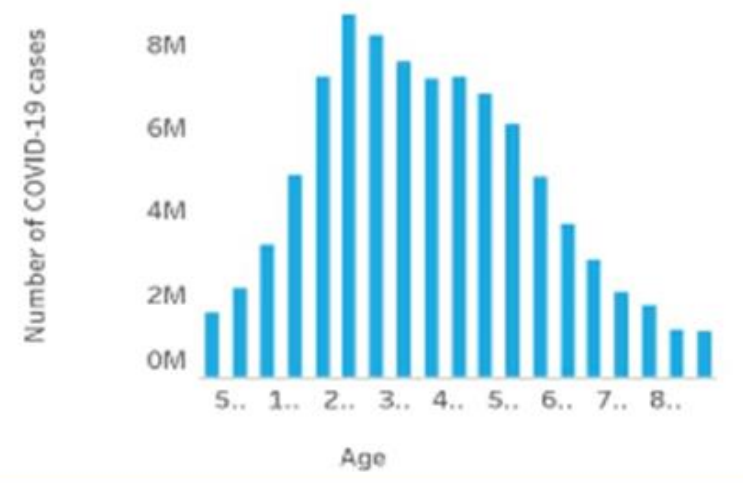

Figure 3: Covid-19 confirmed cases by 5 year age groups
Around 12 million COVID-19 cases occur in children and adolescents, which is 13 percent of the 88 million COVID-19 cases in 100 countries.

The 88 million COVID-19 cases in 100 countries account for 51 percent of the total global cases reported by Johns Hopkins University. COVID-19 data were collected from January 2020 to present and country data were updated on different dates. ${ }^{18}$

\section{Definitions:}

Clinical syndromes associated with covid-19 in children were defined based on WHO classification as follows ${ }^{19,20}$

1) Asymptomatic case- The infection is identified during screening without any symptoms.

2) Mild Case- Fever or fatigue or upper airway symptoms without any radiological findings.

3) Moderate Case-Fever/fatigue/upper airway symptoms like mild respiratory distress/pneumonia identified with chest x-ray.

4) Severe Case-It is associated with fever and cough, along with one of the following:

- Oxygen saturation level $(\mathrm{SpO} 2)<92 \%$

- $\quad$ Severe respiratory distress (grunting, severe chest indrawing, cyanosis, intermittent apnea.

- $\quad$ Fast breathing (regardless of fever and crying)

Respiratory rate (RR) in breaths/minute $>60$ if $<$ 3 months; $>50$ if 3-12 months; 40 if $1-5$ years; $>30$ if $>5$ years of age.

- Systemic symptoms: drowsiness, lethargy, seizures, dehydration.

5)Critical Case-It is seen in case if the child is associated with

- $\quad$ Pediatric acute respiratory distress syndrome

- Sepsis-associated organ dysfunction

- $\quad$ Septic shock

- Coma.

\section{TREATMENT}

Treatment Approaches Based on Different Scenarios

1) Asymptomatic Cases-No Specific Treatment Is Required. These cases can be treated at home. They should be isolated to prevent transmission and monitored for clinical deterioration. The patient should have enough calorie and water intake. ${ }^{21}$

2) Mild and Moderate Cases: Mild cases could be symptomatically treated at home and be assessed for vital signs and oxygen saturation. Moreover, CBC, CRP, blood chemistry, myocardial and liver enzymes, kidney function, and coagulation test results should be assessed if needed, but 
Antipyretic Therapy Is Required. It is preferred to use paracetamol (10-15 mg/kgevery 4-6 h) in case of fever $>38.5{ }^{\circ} \mathrm{C}$. Avoid ibuprofen in case of dehydration, vomiting and diarrhoea, as it is associated with an increased risk of kidney failure. For Cough Throat soothing agents like warm saline gargles can be used. ${ }^{22}$

Children with moderate Covid- 19 diseases should be administered:

i. For fever: Paracetamol 10-15 mg/kg/dose. May be repeated every 4-6 hours.

ii. Amoxycillin to be administered, if there is evidence/ strong suspicion of bacterial infection.

iii. For SpO2 below 92-94\%, oxygen supplementation is required.

iv. Corticosteroids may be administered in rapidly progressive disease. It is not required in all children with moderate illness, specifically during first few days of illness.

v. Supportive care for comorbid conditions, if any. ${ }^{6}$

3)Severe and Critical Cases: children with spo2 levels less than $90 \%$ are considered to be having severe degree of infection. Therefore, Different Therapies and Various Drugs Are Used for children associated with this are-

\section{Anti-viral Therapy:}

Remdesivir: It is one of the drugs approved by the FDA for the treatment of covid-19 in both hospitalized adult and pediatric patients for emergency use as it is not evaluated in clinical trials that include children. It is a nucleotide analogue that is incorporated into viral RNA chain leading to premature termination.

Dosage: If body weight $>40 \mathrm{~kg}: 200 \mathrm{mg}$ on 1st day then 100 $\mathrm{mg}$ once daily for 4 days. If body weight is between $3.5 \mathrm{~kg}$ to $4 \mathrm{~kg}: 5 \mathrm{mg} / \mathrm{kg}$ on $1 \mathrm{st}$ day, $2.5 \mathrm{mg} / \mathrm{kg}$ once daily for 4 days. ${ }^{23,24}$

Hydroxychloroquine ( $\mathrm{HCQ}$ ): It is an antiviral drug where in vitro studies suggest that it could act by increasing the endosomal $\mathrm{pH}$ required for virus / host cell fusion and interfering with the glycosylation of the SARS-Cov-2 cell receptor. In particular, hydroxychloroquine appears to have better in vitro activity towards SARSCoV-2. The antiinflammatory activity of these molecules, through the inhibition of the production of Interleukin (IL) -6 and Tumor Necrosis Factor (TNF)- $\alpha$, could contribute to their effectiveness. In addition, this molecule has been in use for decades, showing a good safety profile.

Dosage: $6 \mathrm{mg} / \mathrm{kg}$ (maximum: $400 \mathrm{mg} /$ dose) twice a day on day 1, followed by $3 \mathrm{mg} / \mathrm{kg}$ (maximum: $200 \mathrm{mg} /$ dose) twice a day for up to 5 days. HCQ solution preparation is mostly recommended for children. ${ }^{25}$

Favipiravir: Favipiravir is an antiviral drug authorized for the treatment of flu. It works by inhibiting RNA polymerase which is RNA-dependent and seems to show a better efficacy compared to lopinavir/ritonavir. Still clinical trials are undergoing to evaluate the efficacy of Favipiravir in SARS-Cov-2 infection in children. ${ }^{26}$

\section{Steroids:}

At present, there are no clear evidences to support the use of steroids during Covid-19 infection unless specific needs in children. The COVID-19 Treatment Guidelines Panel recommends the use of dexamethasone for children who require high-flow oxygen, non-invasive ventilation, invasive mechanical ventilation, or extracorporeal membrane oxygenation (ECMO). If dexamethasone is not available, alternative glucocorticoids such as prednisone, methylprednisolone, or hydrocortisone can be considered.

Dosing regimen for pediatric patients is dexamethasone $0.15 \mathrm{mg} / \mathrm{kg} /$ dose (maximum dose $6 \mathrm{mg}$ ) once daily for up to 10 days. 27,28

Inhalation therapy: If topical steroids and/or bronchodilators are needed (e.g., patient with recurrent wheezing undergoing exacerbation and suggestive symptoms or confirmed SARS-Cov-2 infection) the use of pressurized suspensions with spacer chamber is suggested. Conversely, the use of nebulisers is not recommended in order to avoid particles aerosolization and increased contagiousness. Ongoing steroid treatment should not be stopped once it is started. ${ }^{29}$

\section{Antibiotic therapy:}

The choice to add empirical antibiotic therapy should only be made if there is reasonable evidence of bacterial superinfection.

- Amoxicillin $90 \mathrm{mg} / \mathrm{kg} /$ day in 3 doses,

- Ceftriaxone 80-100 mg/kg/day,

- Azithromycin $15 \mathrm{mg} / \mathrm{kg}$ the first day, then 7.5 $\mathrm{mg} / \mathrm{kg}$ once a day for other 4 days. ${ }^{30}$

\section{Anti-SARS-CoV-2 Monoclonal Antibodies:}

For Drugs like Bamlanivimab, Etesevimab, Casirivimab and Imdevimab EUAs have been issued for the treatment of hospitalized, high-risk patients aged $\geq 12$ years and weighing $\geq 40 \mathrm{~kg}$ with moderate to severe COVID-19, there are currently no data available to determine which is causing high-risk to pediatric patients. Emerging data regarding the prevalence and clinical significance of SARS-CoV-2 variants, and the efficacy of monoclonal antibodies against different variants, may inform the choice of specific anti-SARS-CoV-2 monoclonal antibody therapy in the future. ${ }^{31}$

Multi System Inflammatory Syndrome in Children (MIS-C) A small set of children and young adults with covid-19 infection developed MIS-C. This immune manifestation is also referred to as pediatric multisystem inflammatory syndrome-temporally associated with SARS-CoV-2 (PMISTS), although the case definitions for the syndromes differ slightly. This syndrome was first described in Europe, where previously healthy children with severe inflammation and Kawasaki disease-like features were identified to have current or recent infection with SARS-CoV-2. ${ }^{32,33}$ 


\section{Clinical Manifestations:}

$>$ Fever $>38.0^{\circ} \mathrm{C}$ for $\geq 24$ hours,

$>$ Laboratory Evidence of inflammation shows elevated C-reactive protein, erythrocyte sedimentation rate, fibrinogen, procalcitonin, d-dimer, ferritin, lactic acid dehydrogenase, interleukin (IL)-6, or neutrophils, or reduced lymphocytes or albumin levels,

$>$ Positive for current or recent SARS-CoV-2 infection by RT-PCR, antigen test, or COVID-19 exposure within the 4 weeks prior to the onset of symptoms. ${ }^{34}$

\section{Treatment of MIS-C:}

Drugs to be used in case of Multi System Inflammatory Syndrome in Children in case the child has cardiac dysfunction, shock, coronary involvement, multi organs dysfunction are:

a. Steroids: Methylprednisolone 1 to $2 \mathrm{mg} / \mathrm{kg}$ per day.

b. Intravenous Immunoglobulin $2 \mathrm{~g} / \mathrm{kg}$ over 24 to 48 hours.

c. Antimicrobials

The child needs appropriate supportive care, preferably in ICU. In absence of cardiac dysfunction, shock, coronary involvement, multi organs dysfunction, one may use steroids.

If the child does not improve with the above treatment the other alternative include:
a. Repeat IVIg
b. High dose corticosteroid (Methylprednisolone 10 to $30 \mathrm{mg} / \mathrm{kg} /$ day for 3 to 5 days)

c. Aspirin: 3 to $5 \mathrm{mg} / \mathrm{kg} /$ day $\max 81 \mathrm{mg} /$ day (if thromobosis or Coronary Aneurysm Score is $>2.5$ )

d. Low Molecular Weight Heparin: Enoxaparin: $1 \mathrm{mg} / \mathrm{kg}$ twice daily subcutaneously. Clotting Factor Xa should be between 0.5 to $1 .^{35}$

\section{CONCLUSION}

Although the numbers of infected children and the severity of illness are expected to be low, health professionals need to be prepared to face the situation. The impacts of COVID19 in children may go far beyond health including psychological, economical, educational and others that are beyond the scope of this article. In most affected children the supportive care, oxygen therapy and antibiotics are adequate. Antivirals are not usually recommended but in case of severity used along with corticosteroids, immunoglobulins. This review applied a rigorous search strategy to retrieve relevant articles according to research objectives. This study may provide some evidence for future study.

\section{REFERENCES}

1. Parisa Khoshnevisasl, Mansour Sadeghzadeh, Sara Sadeghzadeh, A Review of COVID-19 in Children, Journal of Comprehensive Paediatrics Official (Quarterly Journal of Iranian Society of Paediatrics).

2. WHO. Coronavirus disease 2019 (COVID-19) Situation Report - 95.2020 , Available from: https://www.who.int/docs/defaultsource/coronaviruse/sit uation-reports/20200424-sitrep-95covid19.pdf?sfvrsn=e8065831 4.

3. Vijesh Sreedhar Kuttiatt, Philip Raj Abraham, Ramesh P. Menon, Pankaj C. Vaidya \& Manju Rahi, Coronavirus disease 2019 in children: Clinical \& epidemiological implications. http://www.ijmr.org.in.

4. Tan WJ, Zhao X, Ma XJ, Wang W, Niu P, Xu W, et al, A novel coronavirus genome identified in a cluster of pneumonia cases - Wuhan, China 2019-2020, China CDC Wkly 2020;2:61-2.

5. Report of the WHO-China Joint Mission on Coronavirus Disease 2019 (COVID-19). Available from: https://www. who.int/docs/default-source/coronaviruse/who-chinajointmission-on-covid-19-final-report.pdf, accessed on March 31, 2020.

6. Protocol for Management of Covid - 19 in the Paediatric Age Group, Government of India Ministry of Health and Family Welfare.

7. Israa Abdul Ameer Al-Kraety, Sddiq Ghani Al-Muhanna, Aaya Hamid Al-Hakeem. Coronavirus-2019 (Covid 19): A Review of History, Epidemology, Structure and Life Cycle.

8. The Novel Coronavirus Pneumonia Emergency Response Epidemiology Team. The epidemiological characteristics of an outbreak of 2019 novel coronavirus diseases (COVID-19) - China, 2020. China CDC Wkly 2020; 2: 113-22.

9. Wang $Q$, Zhang $Y, W u ~ L, ~ N i u ~ S$, Song $C$, Zhang $Z$, et al. Structural and Functional Basis of SARS-CoV-2 Entry by Using Human ACE2. Cell. 2020;181(4):894-904 e9. doi: [PubMed Central: PMC7068984].

10. 1016/j.cell.2020.03.045. [PubMed: 32275855]. [PubMed Central: PMC7144619].Guo YR, Cao QD, Hong ZS, Tan YY, Chen SD, 10. Jin HJ, et al. The origin, transmission and clinical therapies on coronavirus disease 2019 (COVID-19) outbreak - an update on the status. Mil Med Res. 2020;7(1):11. doi: 10.1186/s40779-020-00240-0. [PubMed: 32169119].

11. GaneshS, Jothi priya.A, Lakshminarayanan Arivarasu. ORIGIN, EVOLUTION AND HISTORY OF COVID 19 - A REVIEW. European Journal of Molecular \& Clinical Medicine.

12. Petra Zimmermann, Nigel Curtis, Coronavirus Infections in Children Including COVID-19 An Overview of the Epidemiology, Clinical Features, Diagnosis, Treatment and Prevention Options in Children.

13. Bi $Q, W u Y$, Mei $S$, et al, Epidemiology and transmission of COVID-19 in Shenzhen, China: analysis of 391 cases and 1286 of their close contacts. medRxiv 2020; published online March 4. DOI:10.1101/2020.03.03.20028423 (preprint).

14. Jieru.E. Lin, Andrews Geneslaw, Neuro Science Letters volume 743,19 January 2021,135567 
15. Michael Joseph Lavery, Charles Alexis Bouvier, Ben Thompson, Clinics In Dermatology, Cutaneous manifestations of COVID-19 in children (and adults): A virus that does not discriminate.

16. Hon KL, Leung CW, Cheng WT, et al, Clinical presentations and outcome of severe acute respiratory syndrome in children. Lancet. 2003; 361:1701-1703.

17. Feng $\mathrm{K}$, Yun $\mathrm{YX}$, Wang $\mathrm{XF}$, et al, Analysis of $\mathrm{CT}$ features of 15 children with 2019 novel corona virus infection. ZhonghuaErKe Zazhi.2020;58: E007.

18. https://data.unicef.org/covid-19-and-children/.

19. World Health Organization. Clinical management of severe acute respiratory infection when novel coronavirus (nCoV) infection is suspected: Interim Guidance 13 March 2020. https://www.who.int/publicationsdetail/clinicalmanagement-of-severe-acute-respiratory infection-when-novel-coronavirus-(ncov)-infection-issuspected. Accessed 26 Jun 2020.

20. World Health Organization. Multisystem inflammatory syndrome in children and adolescents with COVID-19. Available:

https://www.who.int/publications/i/item/multisysteminflammatory-syndrome-in-children-andadolescents-withcovid-19. Accessed 16 Jun 2020.

21. Verdoni L, Mazza A, Gervasoni A, Martelli L, Ruggeri M, Ciuffreda $M$, et al,An outbreak of severe Kawasaki-like disease at the Italian epicentre of theSARS-CoV-2 epidemic:an observational cohort study. Lancet. 2020;395:1771-8. https://doi.org/10.1016/S01406736(20)31103-X.

22. Day M. Covid-19: ibuprofen should not be used for managing symptoms, say doctors and scientists. BMJ. 2020;368:m1086. https://doi.org/10.1136/bmj.m1086.

23. Food and Drug Administration, Fact sheet for healthcare providers: emergency use authorization (EUA) of veklury (remdesivir) for hospitalized pediatric patients weighing 3.5 $\mathrm{kg}$ to less than $40 \mathrm{~kg}$ or hospitalized pediatric patients less than 12 years of age weighing at least $3.5 \mathrm{~kg}$. 2020, Available at: https://www.fda.gov/media/137566/download

24. Al-Tawfiq JA, Al-Homoud AH, Memish ZA, Remdesivir as a possible therapeutic option for the COVID-19. Travel Med Infect Dis.

2020. https://doi.org/10.1016/j.tmaid.2020.101615

25. Yao X, Ye F, Zhang M, Cui C, Huang B, Niu P, et al, In Vitro Antiviral Activity and Projection of Optimized Dosing Design of Hydroxychloroquine for the Treatment of Severe Acute
Respiratory Syndrome Coronavirus 2 (SARS-CoV-2). Clin Infect Dis. 2020. https://doi.org/10.1093/cid/ciaa237.

26. Dong L, Hu S, Gao J. Discovering drugs to treat coronavirus disease 2019(COVID-19). Drug Discovery: 2020;14:58-60.

27. Wu C, Chen X, Cai Y, Xia J, Zhou X, Xu S, et al. Risk factors associated with acute respiratory distress syndrome and death in patients with coronavirus disease 2019 pneumonia in Wuhan, China. JAMA Intern Med. 2020https://doi.org/10.1001/jamainternmed.2020.0994.

28. covid-19 treatment guidelines https://www.covid19treatmentguidelines.nih.gov/

29. Global Initiative for Asthma (GINA). Recommendations for inhaled asthma controller medications. March 19, 2020. https://ginasthma.org/recommendations-for-inhaledasthma controller-medications/. Accessed 14Jun 2020.

30. Gautret P, Lagier JC, Parola P, Hoang VT, Meddeb L, Mailhe $M$, et al Hydroxychloroquine and azithromycin as a treatment of COVID-19: results of an open-label nonrandomized clinical trial, AntimicrobAgents.2020.https://doi.org/10.1016/j.ijantimic ag.2020.105949.

31. Wolf J, Abzug MJ, Wattier RL, et al. Initial guidance on use of monoclonal antibody therapy for treatment of COVID-19 in children and adolescents. J Pediatric Infect Dis Soc. 2021; Published online ahead of print. Available at: https://www.ncbi.nlm.nih.gov/pubmed/33388760

32. Riphagen S, Gomez X, Gonzalez-Martinez C, Wilkinson N, Theocharis P. Hyperinflammatory shock in children during COVID-19 pandemic. Lancet. 2020;395(10237):1607-1608. Available https://www.ncbi.nlm.nih.gov/pubmed/32386565.

33. Whittaker E, Bamford A, Kenny J, et al. Clinical characteristics of 58 children with a pediatric inflammatory multisystem syndrome temporally associated with SARSCoV-2, JAMA. 2020;324(3):259-269, Available at: https://www.ncbi.nlm.nih.gov/pubmed/32511692.

34. Centers for Disease Control and Prevention. Information for healthcare providers about multisystem inflammatory syndrome in children (MIS-C). 2021. Available at: https://www.cdc.gov/mis-c/hcp/. Accessed March 26, 2021.

35. Ouldali N, Toubiana J, Antona D, et al. Association of intravenous immunoglobulins plus methylprednisolone vs immunoglobulins alone with course of fever in multisystem inflammatory syndrome in children. JAMA. 2021;325(9):855-864. Available at: https://www.ncbi.nlm.nih.gov/pubmed/33523115.

Source of Support: The author(s) received no financial support for the research, authorship, and/or publication of this article.

Conflict of Interest: The author(s) declared no potential conflicts of interest with respect to the research, authorship, and/or publication of this article.

For any question relates to this article, please reach us at: editor@globalresearchonline.net New manuscripts for publication can be submitted at: submit@globalresearchonline.net and submit_ijpsrr@rediffmail.com 